edition. Quintessence Publishing Co, Inc; 2018, 104-144.

2. Phạm Như Hải. Nghiên Cứu Dịch Tễ Học Loạn Năng Bộ Máy Nhai và Đề Xuất Giải Pháp Can Thiệp, Luận an Tiến sỹ $Y$ học, Trường Đại học $Y$ Hà Nội; 2006.

3. Đoàn Hồng Phượng, Hoàng Tử Hùng. Tình hình rối loạn thái dương hàm ở người lớn (18 - 54 tuổi) tại thành phố Hồ Chí Minh, Y học thành phố Hồ Chí Minh, 11(2), $32-40$.

4. Okeson J. Management of Temporomandibular Disorders and Occlusion. Seventh edition. Mosby; 2013, 1-250.
5. Barghan S, Merrill R, Tetradis S. Cone beam computed tomography imaging in the evaluation of the temporomandibular joint. J Calif Dent Assoc. 2010;38(1):33-39.

6. Mani F. và Sivasubramanian S. A study of temporomandibular joint osteoarthritis using computed tomographic imaging. Biomed J. 2016; 39.

7. Arayasantiparb R., Mitrirattanakul S., Kunasarapun P., et al. Association of radiographic and clinical findings in patients with temporomandibular joints osseous alteration. Clin Oral Investig. 2020; 24, 221-227.

\title{
ĐĂC ĐIỂM LÂM SÀNG, CÂN LÂM SÀNG TIÊU CHẢY CẤP PHÂN MÁU Ở TRẺ EM TẠI BỆNH VIỆN ĐA KHOA ĐỨC GIANG
}

\section{TÓM TẮT}

Tiêu chảy cấp phân máu là tình trạng nhiễm khuẩn đường tiêu hóa thường gặp ở trẻ em, gây ảnh hưởng đến sự phát triển của tré. Mục tiêu nghiên cứu: mố tả đặc điểm lâm sàng, cân lâm sàng tiêu chảy cấp phân máu ở trẻ em. Đối tượng và phương pháp nghiên cứu: Nghiên cứu tiến cứu mô tả một loạt ca bểnh gồm 64 bênh nhân được chẩn đoán tiêu chảy cẩp phân máu vào điều trị tai khoa Nhi bênh viên đa khoa Đức Giang từ tháng 08/2020 đến tháng 05/2021. Kết quả: Tuổi trung bình mắc bênh là 16,6 \pm 14,6 (264) tháng, trong đó $79,6 \%$ trường hợp mắc bệnh dưới hai tuổi. Tî lê mắc bênh trẻ trai/gái là $1,7: 1$. Trẻ đi ngoài phân có nhây máu chiếm $100 \%$. Các triệu chứng lâm sàng thường găp là chán ăn $79,7 \%$, sốt $76,6 \%$, mất nước $35,9 \%$, đau bụng $35,9 \%$ và nôn $34,4 \%$. Các triêu chứng khác kèm theo như hâu môn sưng đỏ 45,3\%, mót rặn khi đi ngoài $40,6 \%$, thiếu máu $37,5 \%$ và bunng chướng $18,8 \%$. Xét nghiêm máu có tăng bach cầu, tăng CRP, hạ Kali, hạ Natri với tỷ lệ lần lượt là $54,7 \%, 70,3 \%, 17,1 \%, 1,6 \%$. Tỷ lệ bạch câu, hồng câu trong phân là $100 \%$ và $78,1 \%$. Cấy phân có Salmonella chiếm 4,7\%. Kết luân: Trẻ tiêu chảy cấp phân máu thường có biểu hiện chán ăn, sốt, hậu môn sưng đỏ, mót rặn khi đi ngoài. Xét nghiệm máu thường gặp tăng bạch câu và CRP. Tỷ lệ phát hiện vi khuẩn qua nuôi cấy phân thấp. khuẩn

Tír khóa: Tiêu chảy cấp phân máu, trẻ em, nhiễm

\section{SUMMARY}

CLINICAL AND LABORATORY CHARACTERISTICS OF ACUTE BLOODY DIARRHEA IN CHILDREN AT THE DUC

${ }^{1}$ Trường Đại học Y Hà Nội

Chịu trách nhiệm chính: Nguyễn Thị Việt Hà

Email: vietha@hmu.edu.vn

Ngày nhân bài: 14.5.2021

Ngày phản biên khoa hoc: 2.7.2021

Ngày duyệt bài: 12.7.2021

\section{Nguyễn Thị Mai Hương1, Nguyễn Thị Việt Hà ${ }^{2}$} GIANG GENERAL HOSPITAL

Acute bloody diarrhea commonly is associated with pathogenic bacteria in pediatric patients, affecting the child's development. Aim: describe the clinical and laboratory characteristics of acute bloody diarrhea in young children. Materials and methods: a case series included 64 patients diagnosed with acute diarrhea stool blood in treatment at Duc Giang General Hospital from August 2020 to May 2021. Results: The mean age of patients was $16.6 \pm 14.6$ (2-64) months, of which $79.6 \%$ happened in children less than two years old. Morbidity rate of male/female is $1,7: 1$. Children with bloody mucus accounted for $100 \%$. Common clinical symptoms were anorexia $79.7 \%$, fever $76.6 \%$, dehydration $35.9 \%$, abdominal pain $35.9 \%$ and vomiting $34.4 \%$. Other accompanying symptoms such as anal swelling and redness $45.3 \%$, pain when defecating $40.6 \%$, anemia $37.5 \%$ and abdominal distension $18.8 \%$. Blood test showed increased leukocytocis and CRP, decreased Kali and Natri with the rates of $54.7 \%, 70.3 \%, 17.1 \%, 1.6 \%$, respectively. The percentage of white blood cells, red blood cells in the stool is $100 \%$ and $78.1 \%$. Fecal culture positive with Salmonella was $4.7 \%$. Conclusion: Children with bloody diarrhea often manifest of anorexia, fever, anal redness, pain when defecating. Blood tests usually show increased leukocytosis and CRP. Positive bacterial culture was low.

Keywords. Bloody diarrhea, children, infection.

\section{I. ĐăT VẤN ĐỀ}

Tiêu chảy là bệnh có tỷ lệ mắc và tử vong cao đứng hàng thứ hai ở trẻ em. Theo thống kê của Tổ chức y tế thế giới, hàng năm có 1,7 tỷ trẻ mắc tiêu chảy với 525000 trường hợp tử vong ${ }^{1}$. Nghiên cứu năm 2010 của Bùi Thị Hồng Thắm cho thấy $\mathrm{E}$. coli chiếm $18,8 \%$ trong số 32 trẻ tiêu máu từ 2 đến 6 tháng tuổi và khoảng $40 \%$ vi khuẩn phân lập được từ phân ${ }^{2}$. 53\% trường hợp tiêu chảy cấp phân máu là do E.coli ở nhóm trẻ 1 tháng đến 5 tuổi được ghi nhận bởi Nguyễn 
Phước Trưởng ${ }^{3}$. Nghiên cứu tại bệnh viện Nhi Trung Ương năm 2018, tiêu chảy nhiễm khuẩn chiếm $11,13 \%$ trong số 602 trẻ mắc tiêu chảy cấp ${ }^{4}$. Nguyễn Thanh Tâm nghiên cứu 42 trường hợp tiêu chảy kéo dài nhiếm khuẩn tại viện Nhi Trung Ương cho kết quả cấy phân $100 \%$ âm tính với vi khuẩn gây bệnh ${ }^{5}$. Một số tác giả khác nghiên cứu về tiêu chảy cấp tỷ lệ cấy phân ra vi khuẩn gây bệnh cũng thấp ${ }^{6-7}$. Tại khoa Nhi bệnh viện đa khoa Đức Giang, tiêu chảy phân máu là triệu chứng nhập viện khá thường gặp nhưng chưa có nghiên cứu nào về vấn đề này. Xuất phát từ vấn đề này chúng tôi tiến hành nghiên cứu với mục tiêu mô tả đặc điểm lâm sàng, cận lâm sàng tiêu chảy cấp phân máu ở trẻ em điều trị tại bệnh viện đa khoa Đức Giang năm 2020-2021.

\section{II. ĐỐI TƯợNG VÀ PHƯƠNG PHÁP NGHIÊN CỨU}

1. Đối tượng. 64 trẻ từ 2 tháng đến 64 tháng tuổi có tiêu chảy cấp phân máu nhập viện điều trị tại khoa Nhi bệnh viện đa khoa Đức Giang từ $1 / 8 / 2020$ đến $30 / 5 / 2021$. Tiêu chuẩn chọn bệnh nhân là các trẻ tiêu chảy cấp phân có máu đại thể trên lâm sàng được làm đây đủ xét nghiệm công thức máu, CRP, điện giải đồ, ure, cre, soi phân, cấy phân ở thới điểm nghiên cứu, người chăm sóc trẻ đồng ý tham gia nghiên cứu và tuân thủ đúng quy trình nghiên cứu. Tiêu chuẩn loại trừ là các trường hợp tiêu chảy cấp do bệnh lý ngoại khoa như lồng ruột, xoắn ruột, trẻ tiểu chảy cẩp phân máu kèm bệnh dị ứng, trẻ mắc bệnh bẩm sinh, mạn tính hoặc người chăm sóc trẻ không đồng ý tham gia nghiên cứu hoặc không tuân thủ đúng quy trình nghiên cứu.

2. Phương pháp. Phương pháp nghiên cứu tiến cứu mô tả hàng loạt ca, chọn cỡ mẫu thuận tiện các bệnh nhân đáp ứng đủ tiêu chuẩn nghiên cứu được đưa vào nghiên cứu. Thu thập số liệu bằng mẫu bệnh án nghiên cứu dựa và̀o phỏng vấn trực tiếp thông tin về tiền sử và bệnh sử cần thiết, khám các triệu chứng lâm sàng và bệnh nhân được làm đây đủ xét nghiệm ở thời điểm nghiên cứu.

3. Xử lý số liệu. Nhập và xử lý số liệu bằng phần mềm SPSS 20.0, sử dụng các phép thống kê mô tả cho biến định lượng và định tính.

4. Đạo đức nghiên cứu. Nghiên cứu được tiến hành dưới sự tuân thủ về mặt y đức, được sự đồng ý của đổi tượng nghiên cứu và đã được thông qua Hội đồng Đạo đức Trường Đại học $Y$ Hà Nội số 455/GCN-HĐĐĐNCYSSH-ĐHYHN ngày 03/03/2021.

\section{KẾT QUẢ NGHIÊN CỨU}

Trong thời gian nghiên cứu từ 01/08/2020 đến 30/05/2021 có 64 trẻ từ 2 tháng đến 64 tháng tuổi có tiêu chảy cấp phân máu nhập viện khoa Nhi, bệnh viện đa khoa Đức Giang đủ tiểu chuẩn lựa chọn được đưa vào phân tích.

Bảng 1. Các đặc điểm của trẻ trong nghiên cứu

\begin{tabular}{|c|c|c|c|}
\hline \multicolumn{2}{|c|}{ Các đặc điểm của trẻ } & $\mathbf{n}$ & $\mathbf{\%}$ \\
\hline & $<6$ tháng & 16 & 25 \\
\cline { 2 - 4 } & $6-12$ tháng & 20 & 31,2 \\
\cline { 2 - 4 } Nhóm tuổi & $13-24$ tháng & 15 & 23,4 \\
\cline { 2 - 4 } & $>24$ tháng & 13 & 20,4 \\
\hline Cân nặng khi sinh < 2500 gram & 1 & 1,6 \\
\hline Bú mẹ hoàn toàn trong 6 tháng đầu & 35 & 54,7 \\
\hline \multicolumn{2}{|c|}{ Suy dinh dưỡng nhẹ } & 3 & 4,7 \\
\hline Tiêm chưng mở rộng đây đủ theo tuối & 63 & 98,4 \\
\hline \multicolumn{2}{|c|}{ Uống vaccine rotavirus } & 46 & 71,9 \\
\hline
\end{tabular}

Nhận xét: Tuổi trung bình của bệnh nhân trong nhóm nghiên cứu là $16,6 \pm 14,6$ tháng, trong đó trẻ em dưới 2 tuổi chiếm $79,6 \%$. Tỉ lệ mắc bệnh ở trẻ trai và trẻ gái là $1,7: 1$, trong đó có $21,9 \%$ trẻ có mắc bệnh nhiễm khuẩn hô hấp cấp kèm theo. $54,7 \%$ trẻ bú me hoàn toàn 6 tháng đầu. Tỷ lệ trẻ tiêm chủng đầy đủ theo chương trình tiểm chủng mở rộng và uống vaccine phòng rotavirus chiếm tỷ lệ lần lượt là $98,4 \%$ và $71,9 \%$.

Bảng 2. Triệu chứng lâm sàng của trẻ tiêu chảy cấp phân máu

\begin{tabular}{|c|c|c|}
\hline Triệu chứng lâm sàng & $\mathbf{n}$ & $\mathbf{\%}$ \\
\hline Sốt & 49 & 76,6 \\
\hline Đau bụng & 23 & 35,9 \\
\hline Mót rặn khi đi ngoài & 26 & 40,6 \\
\hline Hậu môn sưng đỏ & 29 & 45,3 \\
\hline Chán ăn & 51 & 79,7 \\
\hline Nôn & 22 & 34,4 \\
\hline Mất nước & 23 & 35,9 \\
\hline Bụng chướng & 12 & 18,8 \\
\hline Phần nhày máu & 64 & 100 \\
\hline
\end{tabular}

Nhận xét: Các triệu chứng lâm sàng hay gặp là phân nhầy máu $(100 \%)$, chán ăn $(79,7 \%)$, sốt (76,6\%), hậu môn sưng đỏ (45,3\%), mót rặn khi đi ngoài $(40,6 \%)$, mất nước $(35,9 \%)$, đau bụng (35,9\%), nôn (34,4\%).

Bảng 3. Sư thay đổi các chỉ số sinh hóa, huyết học của tré tiêu chảy cấp phân máu

\begin{tabular}{|c|c|c|}
\hline $\begin{array}{c}\text { Các chỉ số sinh hóa, } \\
\text { huyết học }\end{array}$ & $\mathbf{n / N}$ & $\mathbf{\%}$ \\
\hline Thiếu máu & $24 / 64$ & 37,5 \\
\hline Tăng bạch câuu trong máu & $35 / 64$ & 54,7 \\
\hline Tăng CRP & $45 / 64$ & 70,3 \\
\hline Hạ Kali & $11 / 64$ & 17,2 \\
\hline Hạ Natri & $1 / 64$ & 1,6 \\
\hline
\end{tabular}

Nhận xét: $37,5 \%$ trẻ có thiếu máu. Tỷ lệ trẻ có tăng bạch câuu và CRP lần lượt là $54,7 \%$ và 
$70,3 \%$. Tỷ lệ trẻ hạ Kali và Natri là $17,2 \%$ và $1,6 \%$.

Bảng 4. Kết quả xét nghiệm phân

\begin{tabular}{|c|c|c|c|}
\hline \multicolumn{2}{|c|}{ Kết quả xét nghiệm phấn } & n/N & Tỷ lệ \% \\
\hline Xét nghiệm & $\begin{array}{c}\text { Cây phân } \\
\text { dương tính }\end{array}$ & $3 / 64$ & 4,7 \\
\hline vi sinh & $\begin{array}{c}\text { Rota virus } \\
\text { dương tính }\end{array}$ & $2 / 64$ & 3,1 \\
\hline & Có bạch cầu & $64 / 64$ & 100 \\
\hline $\begin{array}{c}\text { Xét nghiêm soi } \\
\text { tươi phân }\end{array}$ & Có hồng cầu & $50 / 64$ & 78,1 \\
\hline & Có nấm & $7 / 64$ & 10,9 \\
\hline & Hạt mỡ & $34 / 64$ & 53,1 \\
\hline Cặn dư phân & Sợi cơ & $7 / 64$ & 10,9 \\
\hline & Tinh bột & $8 / 64$ & 12,5 \\
\hline
\end{tabular}

Nhân xét: Kết quả soi phân thấy $100 \%$ có bạch cẩu, $78,1 \%$ có hồng cầu và $10,9 \%$ có nấm. Tỷ lệ có hạt mõ̃, sợi cơ và tinh bột trong phân lần lượt là $53,1 \%, 10,9 \%$ và $12,5 \%$. Kết quả cấy phân có 3 trường hợp thấy Salmonella (chiếm $4,7 \%$ ) và 2 trường hợp có rota virus (chiếm $3,1 \%)$

\section{BÀN LUÂN}

Trong khoảng thời gian từ tháng 8/2020 đến tháng 5/2021, chúng tôi tiến hành nghiên cứu 64 trẻ bị tiêu chảy cấp phân máu tại bệnh viện đa khoa Đức Giang, kết quả tuổi trung bình của bệnh nhân trong nhóm nghiên cứu là $16,6 \pm 14,6$ (2-64) tháng, trong đó trẻ em dưới 2 tuổi chiếm $79,6 \%$. Kết quả tuổi trung bình của chúng tôi cao hơn nghiên cứu của Nguyễn Phước Trưởng với tuổi trung bình là 9,8 $\pm 8,02$ tháng, trẻ dưới 2 tuổi chiếm tới $95 \%{ }^{3}$. Trẻ trai có xu hướng bị bệnh nhiêu hơn trẻ gái, với tỷ lệ trẻ trai/gái là $1,7: 1$. Kết quả này cũng phù hợp với nhiều nghiên cứu về tiêu chảy cấp trên thế giới và trong nước. Arvola nghiên cứu tại Phần Lan cũng cho kết quả tỷ lệ trai/gái là $1,3: 1^{8}$. Theo nghiên cứu về dịch tể lâm sàng và vi sinh của tiêu chảy cấp phân máu ở trẻ nhỏ tại bệnh viện Nhi đồng I năm 2015 thì tỷ lệ trẻ trai/gái là 1,5:13.

Kết quả từ bảng 2 cho thấy triệu chứng chủ yếu ở trẻ bị tiêu chảy phân máu khi nhập viện trong nghiên cứu của chúng tôi là sốt $(76,6 \%)$, đau bụng $(35,9 \%)$, mót rặn khi đi ngoài $(40,6 \%)$, nôn $(34,4 \%)$, các chỉ số trên cũng tương đồng so với nghiên cứu của Nguyễn Phước Trưởng với tỷ lệ lần lượt là $70 \%, 29 \%$, $29 \%$ và $43 \%{ }^{3}$. Trong ngiên cứu của Nguyễn Ngọc Anh cũng cho thấy sốt, nôn là các triệu chứng hay gặp ở trẻ tiêu chảy cấp $(55,7 \%$ và $59,2 \%)^{8}$. Trong nghiên cứu của chúng tôi có $21,9 \%$ trẻ có nhiễm khuẩn hô hấp cấp tính kèm theo. Kết quả này tương đồng với nghiên cứu của Nguyễn Thanh Tâm có 21,4 trẻ có nhiễm khuẩn kèm theo phần lớn là nhiễm khuẩn hô hấp cấp tính. Tỷ lệ suy dinh dưỡng nhẹ trong nhóm nghiên cứu cửa chúng tôi là $4,7 \%$ thấp hơn so với của Nguyễn Thanh Tâm $(9,5 \%)$. Điều này có thể giải thích do Nguyễn Thanh Tâm nghiên cứu trên trẻ ia chảy kéo dài nhiễm khuẩn nên trẻ dễ bị suy dinh dưỡng hơn 5 .

Kết quả từ bảng 3 cho thấy $54,7 \%$ bệnh nhân được xác định tăng bạch cầu, 70,3\% bệnh nhân tăng CRP. Tỷ lệ trẻ có tăng CRP trong nghiên cứu của chúng tôi tương đương với nghiên cứu của Nguyễn Phan Lương CRP tăng $68 \%$ trường hợp $p^{4} .37,5 \%$ trẻ trong nghiên cứu có thiếu máu trong đó chủ yếu là thiếu máu nhẹ. Kết quả này tương đồng với nghiên cứu của Bùi Thị Hồng Thắm với tỷ lệ thiếu máu là $31 \%{ }^{2}$. Tỷ lệ trẻ bị hạ Kali và hạ Natri trong nghiên cứu của chúng tôi là $17,2 \%$ và $1,6 \%$, mức độ hạ Kali nhẹ từ 3,2$3,4 \mathrm{mmol} / \mathrm{L}$.

Bạch cầu và hồng cầu trong phân là các dấu ấn giúp chẩn đoán tiêu chảy nhiếm khuẩn. Theo nghiên cứu của chúng tôi trong 64 trường hợp tiêu chảy phân có nhày máu $100 \%$ soi phân có số lượng bạch cầu trên tiêu bản ở mức độ trung bình đến nẳng, $78,1 \%$ trẻ có hồng cầu và $10,9 \%$ có nấm (bảng 4). Tỷ lệ trẻ có bạch cầu và hồng cầu trong phân của chúng tôi cao hơn so với nghiên cứu của Nguyễn Phước Trưởng với bạch cầu trong phân chiếm $74 \%$ và hồng cầu trong phân có $9 \%{ }^{3}$, và Bùi Thị Hồng Thắm với tỷ lệ bạch cầu và hồng cầu trong phân lần lượt là $46,2 \%$ và $26,9 \%^{2}$. Kết quả cặn dư phân trong nghiên cứu của chúng tôi tỷ lệ phát hiện hạt mõ , sợi cơ, tinh bột lần lượt là $53,1 \%, 10,9 \%$ và $12,5 \%$. Kết quả phân có hạt mõ của chúng tôi cao hơn nghiên cứu của Nguyễn Phan Lương với tỷ lệ hạt mõ trong phân là $36,7 \%{ }^{4}$, và cao hơn so với nghiên cứu của Nguyễn Thanh Tâm với hạt mõ trong phân là $23,8 \% \%^{5}$. Tỷ lệ trẻ có sợi cơ trong phân trong nghiên cứu của chúng tôi tương đương so với nghiên cứu của Nguyễn Thanh Tâm (9,5\%). Xét nghiệm cấy phân dương tính trong nghiên cứu của chúng tôi rất thấp, chì 4,7\% trường hợp phát hiện có Salmonella, tương đương với nghiên cứu của Addisu Assefa $(6,3 \%)^{9}$, nhưng thấp hơn so với nghiên cứu của Nguyễn Phước Trưởng tại bệnh viện Nhi đồng I với tỷ lệ cấy phân dương tính $53 \% \%^{3}$. Trong khi đó nghiên cứu của tác giả Nguyễn Thanh Tâm trên nhóm trẻ dưới 24 tháng tiêu chảy kéo dài nhiễm khuẩn không phát hiện được vi khuẩn bằng cấy phân ${ }^{5}$. Điêu này có thể giải thích do bệnh nhân trong nhóm nghên cứu của Nguyễn Thanh Tâm được dùng kháng sinh trước khi đến 
viện là $88,1 \%$ nên cấy phân khó tìm ra vi khuẩn gầy bệnh.

\section{KẾT LUẬN}

Trẻ tiêu chảy cấp phân máu thường có biểu hiện chán ăn, sốt, hậu môn sưng đỏ, mót rặn khi đi ngoài. Xét nghiệm máu thường gặp tăng bạch cầu và CRP. Tỷ lệ phát hiện vi khuẩn qua nuôi cấy thấp.

\section{TÀI LIÊU THAM KHẢO}

1. WHO, Diarrhoeal disease. 2017.

2. Bưi Thị Hồng Thắm, Nguyễn Anh Tuấn. Hoàng Lê Phúc. Đặc điểm của tiêu máu ở trẻ em từ $2-6$ tháng tuổi tại khoa Tiêu hóa BV Nhi đồng I. Tạp chí nghiên cứu y học. 2010;15(3): 160-164.

3. Nguyê̂n Phước Trướng. (2015). Đạ̣c điểm dịch tê̂, lâm sàng và vi sinh tiêu chảy cấp phân máu ở tré nhỏ.Luận văn bác sĩ chuyên khoa cấp II. Trường đại học Y Dược Thành phố Hồ Chí Minh.

4. Nguyển Phan Lượng. (2018). Nghiên cứu một sổ đạc điểm dịch tể học, lâm sang, cận lâm sàng tiêu chảy cấp do vi khuẩn ở trẻ em điêu trị tại bệnh viện nhi trung ương. Luận văn thạc sỹ y học. Trường đại học Y Hải Phòng.
5. Nguyễn Thị Thanh Tâm, Nguyễn Thị Việt Hà, Đảnh giá một số yếu tô nguy cơ của tiêu chảy kéo dài nhiềm khuẩn ở trẻ em $6-24$ tháng tuổi tai bênh viên Nhi trung, Tạp chí $Y$ học thực hànhi. 2017; 10ं48: 87-90

6. Lê Công Dần, Ngôo Thị Thi, Bùi Thị Mùi và cộng sự. Tỷ lế nhiềm và mức độ đáp ứng kháng sinh của các vi sinh vât gây bênh ở bênh nhân mắc tiêu chảy tại bệnh viện nhi Trung ướng. Tạp chí nghiên cứu y học. 2006;44(4): 52-55

7. Arvola T, et al (2006), "Rectal bleeding in infancy: Clinical, allergological, and micrbiological examination.", Pediatrics, (117), pp. 760-768,

8. Hoàng Ngọc Anh, Đặng Thị Thúy Hà, Lương Thị Nghiếm. Đặc điểm lâm sàng, cận lâm sàng của bệnh nhi tiêu chảy cấp tại bệnh viện Nhi Trung ương. Tap Chí Nghiên cứu và Thực hành Nhi khoa. 2020; 4(3): $50-54$

9. Addisu Assefa, Mengistu Girma (2019). "Prevalence and antimicrobial susceptibility patterns of Salmonella and Shigella isolates among children aged below five years with diarrhea attending Robe General Hospital and Goba Referral Hospital, South East Ethiopia" Trop Dis Travel Med Vaccines 5, 19 https://doi.org/10.1186/s40794-019-0096-6

\section{HIỆU QUẢ BỔ SUNG SỮA CÔNG THỨC LÊN TÌNH TRẠNG DINH DƯỡNG, SỨC KHỎE CỦA TRẺ 36-60 THÁNG TÛ̉I}

\section{TÓM TẮT}

Nghiên cứu can thiệp có đối chứng nhằm đánh giá hiệu quả bổ sung sữa công thức lên tình trạng dinh dữ̛̃ng, sức khỏe đối với trẻ 36-60 tháng tuổi. Nghiên cứu được hoàn thành tại Thái Bình vào tháng 5/2019 với 89 trẻ nhóm can thiệp bổ sung sữa công thức 2 lần/ngày trong 3 tháng và̀ 90 trẻ nhóm chứng với chế độ ăn thông thường. Kêt quả nghiên cứu cho thấy bổ sung sữa công thức đã có tác động tích cực ở nhóm can thiệp so với nhóm chứng: tăng cân, tăng chiêu cao sau 2 tháng can thiệp với mức có ý nghĩa thống kê $(p<0,05)$. Sau 4 tháng can thiêpp, mức tăng cân nặng trung bình nhiêu hơn $0,4 \mathrm{~kg}(1,5 \pm 0,4 \mathrm{~kg}$ so với $1,1 \pm 0,6 \mathrm{~kg})$; mức tăng chiêu cao trung bình nhiều hơn $0,5 \mathrm{~cm}(2,6 \pm 0,8 \mathrm{~cm}$ so với $2,1 \pm 0,8 \mathrm{~cm})$ với mức có ý nghĩa thống kê $(p<0,05)$; Cải thiện tình trạng biếng ăn với mức có ý nghĩa thống kê $(p<0,05)$. Có xu hướng cải thiện tình trạng nhiểm khuẩn hố hấp, khó ngủ nhưng số không có ý nghĩa thống kê $(p>0,05)$.

Tư khóa: đa vi chất, sữa công thức, trẻ mẫu giáo, chiều cao, cân nặng

\footnotetext{
1 Trường Đại hoc Y Hà Nôi

2Viện Y học Ứng dụng Việt Nam

Chịu trách nhiệm chính: Phạm Quốc Hùng

Email: phamquochung@hmu.edu.vn

Ngày nhận bài: 14.5.2021

Ngày phản biện khoa học: 5.7.2021

Ngày duyệt bài: 16.7.2021
}

Phạm Quốc Hùng', Phạm Văn Hoan²

\section{SUMMARY}

\section{EFFECTS OF FORMULA SUPPLEMENT ON NUTRITION STATUS AND HEALTH OF PRESCHOOL CHILDREN AGED 36-60 MONTHS}

A controlled intervention study evaluated the effect of formula supplementation on nutritional status and health of children aged 36-60 months. The study was completed in Thai Binh in May 2019 with 89 children in the intervention group supplementing with formula milk twice a day for 3 months, and 90 children in the control group with a regular diet. The study results showed that supplementing with formula had a positive effect in the intervention group compared with the control group: weight gain, height increase after 2 months of intervention with statistical significance $(p<0.05)$. The average weight gain was $0.4 \mathrm{~kg}$ more $(1.5 \pm 0.4 \mathrm{~kg}$ versus $1.1 \pm 0.6 \mathrm{~kg})$; the average height increase was $0.5 \mathrm{~cm}$ more $(2.6 \pm 0.8 \mathrm{~cm}$ versus $2.1 \pm 0.8 \mathrm{~cm})$ with statistical significance $(p<0.05)$; There was improved anorexia with statistical significance $(p<0.05)$. There was a tendency to improve respiratory infections and sleep problems, but the differencies were not statistically significant $(p>0.05)$.

Keywords: micronutrients, formula milk, preschool student, height, weight

I. ĐẶT VẤN ĐỀ

Tình trạng suy dinh dưỡng (SDD) của trẻ em, 